\title{
A New Photocatalytic System Using Steel Mesh and Cold Cathode Fluorescent Light for the Decolorization of Azo Dye Orange G
}

\author{
Ming-Chin Chang, ${ }^{1}$ Chin-Pao Huang, ${ }^{2}$ Hung-Yee Shu, ${ }^{1}$ and Yung-Chen Chang ${ }^{1}$ \\ ${ }^{1}$ Institute of Environmental Engineering, Hungkuang University, 34 Chung-Chie Road, Shalu, Taichung 433, Taiwan \\ ${ }^{2}$ Department of Civil and Environmental Engineering, University of Delaware, Newark, DE 19716, USA
}

Correspondence should be addressed to Hung-Yee Shu, hyshu@sunrise.hk.edu.tw

Received 1 June 2012; Accepted 23 June 2012

Academic Editor: Mika Sillanpää

Copyright ( 12012 Ming-Chin Chang et al. This is an open access article distributed under the Creative Commons Attribution License, which permits unrestricted use, distribution, and reproduction in any medium, provided the original work is properly cited.

\begin{abstract}
High color and organic composition, the effluents from the textile dyeing and finishing industry, can be treated by photocatalytic oxidation with $\mathrm{UV} / \mathrm{TiO}_{2}$. The objective of this study was to prepare a new photocatalytic system by coating nanosized $\mathrm{TiO}_{2}$ particles on steel mesh support and using cold cathode fluorescent light (CCFL) irradiation at $365 \mathrm{~nm}$ in a closed reactor for the oxidation of azo dye C.I. Orange $\mathrm{G}(\mathrm{OG})$. Various factors such as reaction time, coating temperature, $\mathrm{TiO}_{2}$ dosage, $\mathrm{pH}$, initial dye concentration, and service duration were studied. Results showed efficient color removal of the OG azo dye by the photocatalytic system with $\mathrm{TiO}_{2}$-coated temperature at $150^{\circ} \mathrm{C}$. The optimal $\mathrm{TiO}_{2}$ dosage for color removal was $60 \mathrm{~g} \mathrm{~m}^{-2}$. An acidic $\mathrm{pH}$ of $2.0 \mathrm{was}$ sufficient for photocatalytic oxidation whereas basic condition was not. The rate of color removal decreased with increase in the initial dye concentration. The $\mathrm{TiO}_{2}$-coated steel mesh can be used repeatedly over 10 times without losing the photocatalytic efficiency. Results of FTIR and IC indicated the breakage of $\mathrm{N}=\mathrm{N}$ bonds, with sulfate as the major and nitrite and nitrate as the minor products, which implied degradation of dye molecules.
\end{abstract}

\section{Introduction}

Most dyestuffs from the effluent of textile dyeing and finishing industry are organic compounds with high color intensity, recalcitrant to conventional biological wastewater treatment, and thus of major environmental concerns [1-4]. Furthermore, chemical coagulation integrated with activated sludge process was not able to meet the increasingly stringent criteria of color in dye wastewater treatment in Taiwan [5]. There is great demand of technology to decolorize the highly colored dye wastewater more effectively. Azo dyes with nitrogen double bond $\mathrm{N}=\mathrm{N}$ are the largest class of commercial dyestuffs used in the textile industries. There were reports of successful color removal with final mineralization from azo dye wastewater using advanced oxidation processes (AOPs) such as $\mathrm{UV} / \mathrm{H}_{2} \mathrm{O}_{2}[6-9], \mathrm{UV} / \mathrm{O}_{3}[10,11]$, or Fenton reaction $[12,13]$. Additionally, it has been reported that photocatalytic processes such as $\mathrm{UV}-\mathrm{TiO}_{2}$ system can also be effective in treating dye wastewaters [14-18] except that when applied in suspension further separation of $\mathrm{TiO}_{2}$ particles is necessary. Therefore, fixing the $\mathrm{TiO}_{2}$ particles onto supported materials such as silica gel and plates can avoid the particle separation step and enables the easy operation of heterogeneous $\mathrm{TiO}_{2}$ photocatalysis [19-23]. The objective of this study was to study the degradation of azo dye C.I. Orange $\mathrm{G}(\mathrm{OG})$ using a batch photocatalytic reactor in which the photocatalytic $\mathrm{TiO}_{2}$ particles were coated on steel mesh and cold cathode fluorescent lamp (CCFL) was used (wavelength of $365 \mathrm{~nm}$ ) as the source of irradiation. The CCFL lamp has thin and simple structure, is less temperature sensitive, and is easy to configure as well as it is brighter than the traditional mercury arc mercury lamp. It is more durable than other light sources. CCFL light is time-saving and less cost which is used broadly in computer products and applications such as liquid crystal display (LCD) backlight displays, PC case lights, and scanners, photocopy machines, industry machines such as appliance lighting, automotive fittings such as dashboard backlights, decoration light, advertisement such as signage board, exit light, and light box, and decoration such as indoors light and 


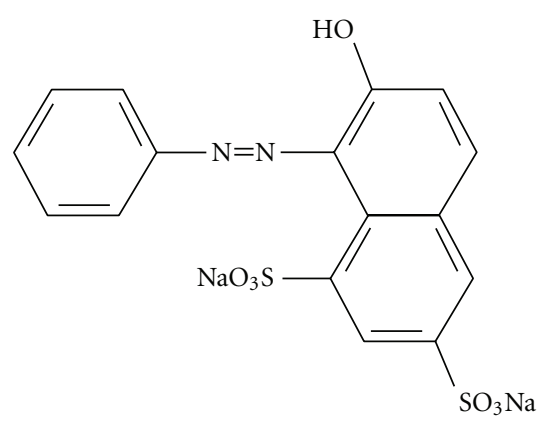

Figure 1: The chemical structure of monoazo dye Orange G. $\left(\mathrm{C}_{16} \mathrm{H}_{10} \mathrm{~N}_{2} \mathrm{Na}_{2} \mathrm{O}_{7} \mathrm{~S}_{2}\right)$.

outdoors light. Factors such as coating temperature, $\mathrm{TiO}_{2}$ dosage, $\mathrm{pH}$, initial dye concentration, and reaction time that may affect the degree of the dye degradation were studied. Changes in color intensity, $\mathrm{pH}$, and ORP were monitored in addition to the analysis of reaction products by FTIR and IC.

\section{Materials and Methods}

2.1. Materials and Apparatus. The monoazo dye, C.I. Orange $\mathrm{G}\left(\mathrm{OG}, \mathrm{C}_{16} \mathrm{H}_{10} \mathrm{~N}_{2} \mathrm{Na}_{2} \mathrm{O}_{7} \mathrm{~S}_{2}, 60 \%\right)$ with a molecular weight of 452.38 and a characteristic wavelength $\left(\lambda_{\max }\right)$ of $479 \mathrm{~nm}$ was purchased from Sigma-Aldrich, Inc., and used as received without further purification. Figure 1 shows the chemical structure of OG. The commercial nanosized titanium dioxide $\left(\mathrm{TiO}_{2}\right)$, Degussa P-25, with a specific surface area of $48.68 \mathrm{~m}^{2} \mathrm{~g}^{-1}$ from Aldrich was used as the catalyst. The steel mesh (mesh size number 140, $0.106 \mathrm{~mm}$ ) was purchased from a local hardware store and trimmed into pieces with a gross area of $252 \mathrm{~cm}^{2}(36 \times 7 \mathrm{~cm})$. Initially, the steel mesh was trimmed, washed with distilled water, dried at room temperature $\left(25^{\circ} \mathrm{C}\right)$, weighed, and then stored in desiccator for further use. A given amount of Degussa P-25 TiO nanoparticle (e.g., $7.5-50.0 \mathrm{~g}$ ) was mixed with $250 \mathrm{~mL}$ of distilled water to make suspension at concentrations of 30$200 \mathrm{~g} \mathrm{~L}^{-1}$. The pretreated steel mesh piece was dipped in the $\mathrm{TiO}_{2}$ suspension then dried under certain temperature for one hour. The steel mesh piece was then washed with distilled water to remove any loose $\mathrm{TiO}_{2}$ particles from the surface. The dipping, washing, and drying steps were repeated three times to reach a certain weight of $\mathrm{TiO}_{2}$ on the steel mesh surface. Table 1 shows the amount of $\mathrm{TiO}_{2}$ coated on the steel mesh surface (gross area of $252 \mathrm{~cm}^{2}$ ) in the range of $0.3025-1.6855 \mathrm{~g}$ which yielded specific surface $\mathrm{TiO}_{2}$ concentration in the range of $12-67 \mathrm{~g} \mathrm{~m}^{-2}$. Based on images obtained with Field Emission Scanning Electron Microscope (FESEM), model JEOL 6330CF, of the $\mathrm{TiO}_{2}$-coated steel mesh, it is seen that $\mathrm{TiO}_{2}$ particles were uniformly coated on the steel mesh surface as shown in Figure 2. The crystallinity of $\mathrm{TiO}_{2}$ particles was characterized by XRD (Thin-Film Xray Diffractometer, $\mathrm{X}-\mathrm{RAY} / \mathrm{TF}$ ) which yielded an anatase to rutile ratio of $7: 3$ as expected. Table 2 shows the BET surface area and porosity of $\mathrm{TiO}_{2}$-coated steel mesh as a function of drying temperature using Micromeritics Gemini V. The

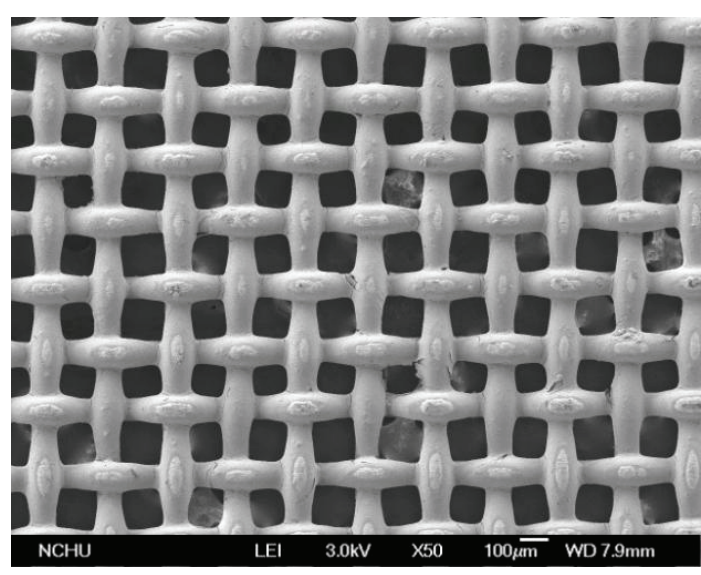

(a)

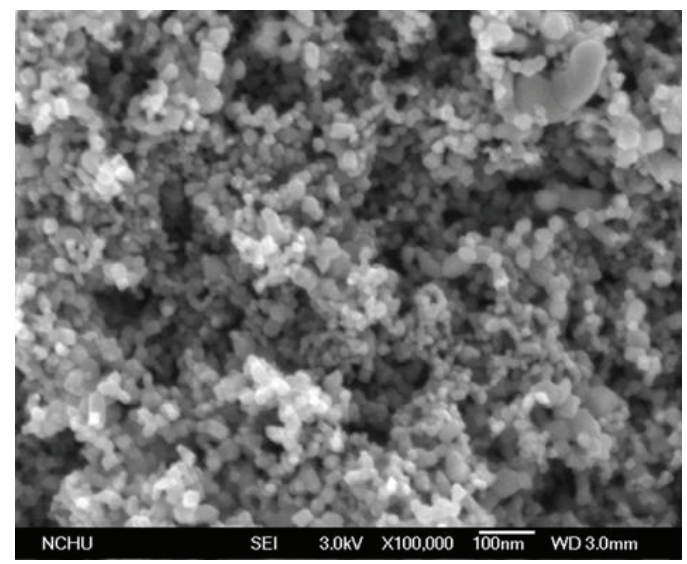

(b)

FIgUre 2: The morphology of $\mathrm{TiO}_{2}$ powder coated on steel mesh at $150^{\circ} \mathrm{C}$ was identified by a JEOL 6330CF Field Emission Scanning Electron Microscope (FESEM). (a) 50 times enlargement and (b) 100,000 times enlargement.

photocatalytic reactor was a closed rectangular black tank (length $\times$ width $\times$ height equal to $360 \times 70 \times 78 \mathrm{~mm}$ ) made of acrylic resin with a removable upper cover underneath of which was six cold cathode fluorescent lamps (CCFL) each of which has a diameter of $0.25 \mathrm{~cm}$, length of $30 \mathrm{~cm}$, light intensity of $4 \mathrm{~W}$, and irradiation wavelength of $365 \mathrm{~nm}$. The dye solution, $200 \mathrm{~mL}$, was introduced to the photocatalytic reactor at which bottom was placed the $\mathrm{TiO}_{2}$-coated steel mesh with total gross surface area $252 \mathrm{~cm}^{2}$ (power per unit area of one lamp of $0.35 \mathrm{~mW} \mathrm{~cm}^{-2}$ ); the depth of the dye solution was $0.794 \mathrm{~cm}$ neglecting the thickness of the steel mesh. The CCFL lamps were located $6.0 \mathrm{~cm}$ above the surface of the dye solution which yielded a total light energy of $2.1 \mathrm{~mW} \mathrm{~cm}^{-2}$ measured at the surface of the solution.

2.2. Photocatalytic Procedure. OG azo dye solution at various concentrations was prepared with deionized water. The experimental variables studied included reaction time, $\mathrm{TiO}_{2}$ dosage, initial dye concentration, and application duration of $\mathrm{TiO}_{2}$. At a predetermined reaction time, an aliquot of the solution was withdrawn and analyzed for residual 
TABLe 1: The $\mathrm{TiO}_{2}$-coated weight on the steel meshes.

\begin{tabular}{lccc}
\hline $\begin{array}{l}\mathrm{TiO}_{2} \text { weight }(\mathrm{g}) \\
\left(\mathrm{W}_{1}\right)\end{array}$ & $\begin{array}{c}\mathrm{TiO}_{2} \text { solution concentration }\left(\mathrm{g} \mathrm{L}^{-1}\right) \\
\left(\mathrm{W}_{1} / \mathrm{V}\right)\end{array}$ & $\begin{array}{c}\mathrm{TiO}_{2} \text { weight on the coated steel meshes }(\mathrm{g}) \\
\left(\mathrm{W}_{2}\right)\end{array}$ & $\begin{array}{c}\mathrm{TiO}_{2} \text { weight per unit area }\left(\mathrm{g} \mathrm{m}^{-2}\right) \\
\left(\mathrm{W}_{2} / \mathrm{A}\right)\end{array}$ \\
\hline 7.5 & 30 & 0.3025 & 12 \\
12.5 & 50 & 0.5098 & 20 \\
25.0 & 100 & 1.0149 & 40 \\
37.5 & 150 & 1.5054 & 60 \\
50.0 & 200 & 1.6855 & 67 \\
\hline
\end{tabular}

$\mathrm{V}$ : the $\mathrm{TiO}_{2}$ solution of $250 \mathrm{~mL}$, A: the steel net area of $252 \mathrm{~cm}^{2}$.

TABLE 2: The specific surface area and porosity of $\mathrm{TiO}_{2}$ by various drying temperature for samples with $\mathrm{TiO}_{2}$ load of $60 \mathrm{~g} \mathrm{~m}^{-2}$.

\begin{tabular}{lcc}
\hline Drying temperature ${ }^{\circ} \mathrm{C}$ & Specific surface area $\mathrm{m}^{2} \mathrm{~g}^{-1}$ & Porosity $\AA$ \\
\hline 100 & 39.41 & 9.4077 \\
150 & 43.35 & 8.8541 \\
200 & 49.76 & 8.4902 \\
250 & 61.42 & 9.1983 \\
300 & 55.35 & 8.3969 \\
\hline
\end{tabular}

dye concentration, TOC, and color. Dye concentration was determined by measuring the absorbance at wavelength of $479 \mathrm{~nm}$ using Hitachi U-2000 spectrophotometer. TOC was obtained with a Total Organic Carbon Analyzer from O.I. Analytical Aurora, model 1030. Color intensity was determined based on the American Dye Manufacturers Institute (ADMI) standard color measurement by applying the Adams-Nickerson color difference formula following method 2120E of the Standard Methods. The $\mathrm{pH}$ and redox potential (ORP) were monitored by a Eutech PH5500 dual channel $\mathrm{pH} / \mathrm{ion}$ meter with specific probes. Besides, the degradation products were identified using Perkin Elmer FT-IR spectrophotometer model Spectrum One. Ions such as sulfate, nitrate, and nitrite were identified with ion chromatography (IC), Dionex ICS-1000.

\section{Results and Discussion}

3.1. Effect of Combining CCFL UV 365 Irradiation and $\mathrm{TiO}_{2}$ Catalyst. The color removal was first compared for various systems, that is, $\mathrm{CCFL} / \mathrm{TiO}_{2}, \mathrm{CCFL}$ alone, and $\mathrm{TiO}_{2}$ alone at the initial OG concentration of $50 \mathrm{mg} \mathrm{L}^{-1}, \mathrm{TiO}_{2}$ dosage of $60 \mathrm{~g} \mathrm{~m}^{-2}$ and 6 CCFL lamps with total light intensity of $24 \mathrm{~W}$ at wavelength of $365 \mathrm{~nm}$ in $120 \mathrm{~min}$ of reaction in the closed reactor. Figure 3 shows results of color removal by various systems. Results indicated that the system of CCFL alone, and $\mathrm{TiO}_{2}$ alone could not remove color at any significant level. The CCFL/TiO 2 system removed color and TOC effectively with almost 100 and 95\% removal, respectively, in $2 \mathrm{~h}$. It was also observed that the $\mathrm{pH}$ remained relatively constant from 5.5 to 5.0 with time. This was expected as $\mathrm{TiO}_{2}$ is a known photocatalyst that upon radiation with light which wavelength is shorter than that of its bandgap can generate hydroxyl radicals, strong oxidation agents that can oxidize a wide group of organic compounds nonspecifically [14-18].

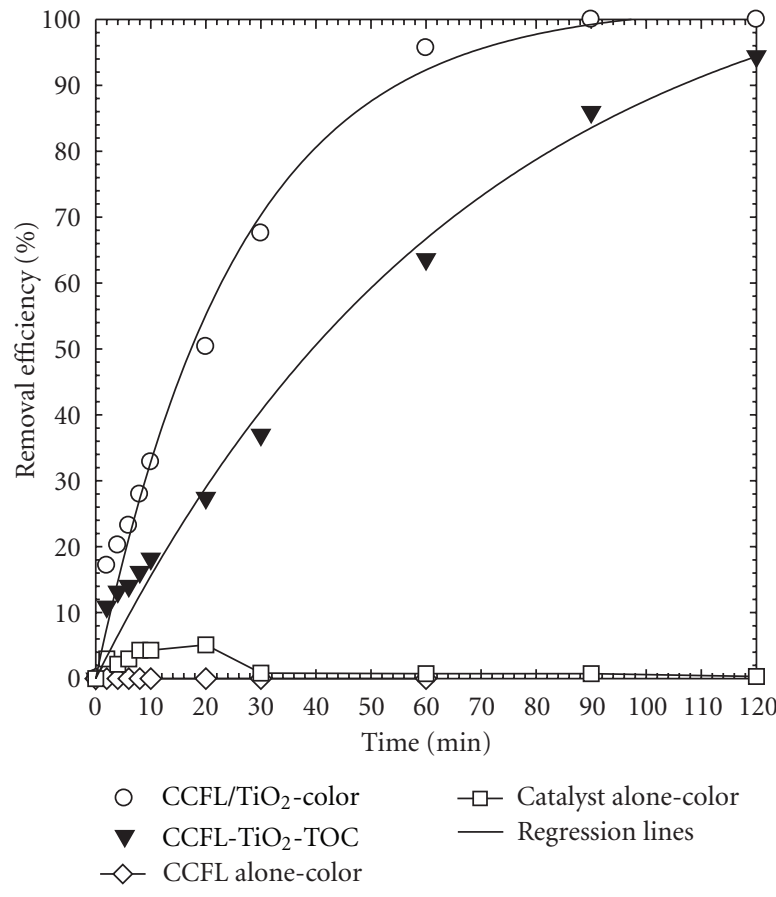

FIgURE 3: Effect of combining CCFL UV 365 irradiation and $\mathrm{TiO}_{2}$ catalyst. The conditions were initial dye concentration of $50 \mathrm{mg} \mathrm{L}^{-1}$, $\mathrm{TiO}_{2}$ coated amounts of $60 \mathrm{~g} \mathrm{~m}^{-2}$, light intensity of $2.1 \mathrm{~mW} \mathrm{~cm}^{-2}$, and reaction time during $120 \mathrm{~min}$.

3.2. Effect of Coating Temperature. The effect of $\mathrm{TiO}_{2}$-coating temperature on color removal was studied at the initial OG concentration of $50 \mathrm{mg} \mathrm{L}^{-1}$, $\mathrm{TiO}_{2}$ load dosage of $40 \mathrm{~g} \mathrm{~m}^{-2}$ and 6 CCFL lamps in $120 \mathrm{~min}$ in the closed reactor. Figure 4 shows insignificant color removal in the range of 100 $300^{\circ} \mathrm{C}$. It was noted that $\mathrm{pH}$ remained unchanged at around 5 to 6 . The reaction kinetics of $\mathrm{UV} / \mathrm{TiO}_{2}$ photocatalytical system was proved to follow the Langmuir-Hinshelwood (L$\mathrm{H})$ reaction kinetics [24-27]. And in most of the designed reaction conditions, the $\mathrm{L}-\mathrm{H}$ kinetic model of the $\mathrm{UV} / \mathrm{TiO}_{2}$ system can be further simplified into pseudo-first-order reaction kinetics. Therefore, the color removal of this study was treated using pseudo first-order reaction as follows:

$$
C_{\text {dye }}=C_{\text {dye } 0} \times e^{-k t},
$$

where $k$ denotes the observed first-order reaction rate constant $\left(\mathrm{min}^{-1}\right), t$ is the reaction time $(\mathrm{min}), C_{\mathrm{dye}, 0}$ designates 


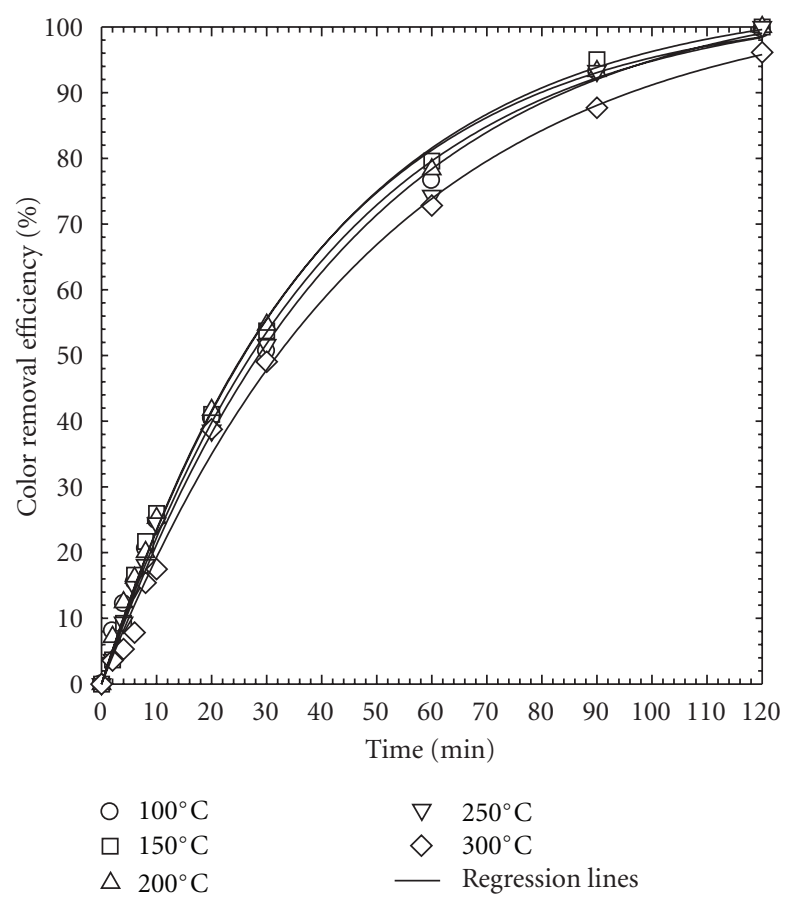

FIGURE 4: Effect of drying temperature. The conditions were initial dye concentration of $50 \mathrm{mg} \mathrm{L}^{-1}, \mathrm{TiO}_{2}$-coated amounts of $40 \mathrm{~g} \mathrm{~m}^{-2}$, light intensity of $2.1 \mathrm{~mW} \mathrm{~cm}^{-2}$, and reaction time during $120 \mathrm{~min}$.

the initial concentration $\left(\mathrm{mg} \mathrm{L}^{-1}\right)$ of $\mathrm{OG}$ and $C_{\mathrm{dye}, t}$ is the concentration $\left(\mathrm{mg} \mathrm{L}^{-1}\right)$ of $\mathrm{OG}$ at time $t$. The curve fitting of experimental results by (1) were shown in the figures as solid lines to present well-fit of kinetic model to the experimental data. The calculated rate constants (from curve fitting) were 2.36, 2.62, 2.52, 2.27, and $2.2310^{-2} \mathrm{~min}^{-1}$ at 100, 150, 200, 250 , and $300^{\circ} \mathrm{C}$, respectively, as shown in Table $3(\mathrm{a})$. The best rate occurred at a coating temperature of $150^{\circ} \mathrm{C}$. Note that this temperature was chosen further as the working condition.

3.3. Effect of $\mathrm{TiO}_{2}$ Load Dosage. Figure 5 shows the removal of color as a function of surface dosage of $\mathrm{TiO}_{2}$. Results indicated that the color removal increased from 80 to $100 \%$ in $120 \mathrm{~min}$ when the surface loading of $\mathrm{TiO}_{2}$ particles increased from 12 to $60 \mathrm{~g} \mathrm{~m}^{-2}$. The color removal then decreased from 100 to $90 \%$ when the surface loading of $\mathrm{TiO}_{2}$ increased from 60 to $67 \mathrm{~g} \mathrm{~m}^{-2}$. An optimal $\mathrm{TiO}_{2}$ loading for color removal occurred at $60 \mathrm{~g} \mathrm{~m}^{-2}$. The rate constants followed similar trend as percent color removal; the observed rate constants were 1.10, 1.41, 2.41, 3.23, and $2.80\left(10^{-2} \mathrm{~min}^{-1}\right)$ at surface $\mathrm{TiO}_{2}$ loading dosage of 12,20 , 40,60 , and $67 \mathrm{~g} \mathrm{~m}^{-2}$, respectively, as shown in Table $3(\mathrm{~b})$. Note that the maximum rate constant also occurred at $\mathrm{TiO}_{2}$ loading of $60 \mathrm{~g} \mathrm{~m}^{-2}$.

3.4. Effect of $p H$. The effect of $\mathrm{pH}$ on the degradation of azo dye was conducted by adjusting the initial $\mathrm{pH}$ value of 5.3 to the range of 2 to 11 using $\mathrm{HCl}$ and/or $\mathrm{NaOH}$ with initial OG dye concentration of $50 \mathrm{mg} \mathrm{L}^{-1}$ and $60 \mathrm{~g} \mathrm{~m}^{-2}$ of $\mathrm{TiO}_{2}$ dosage.

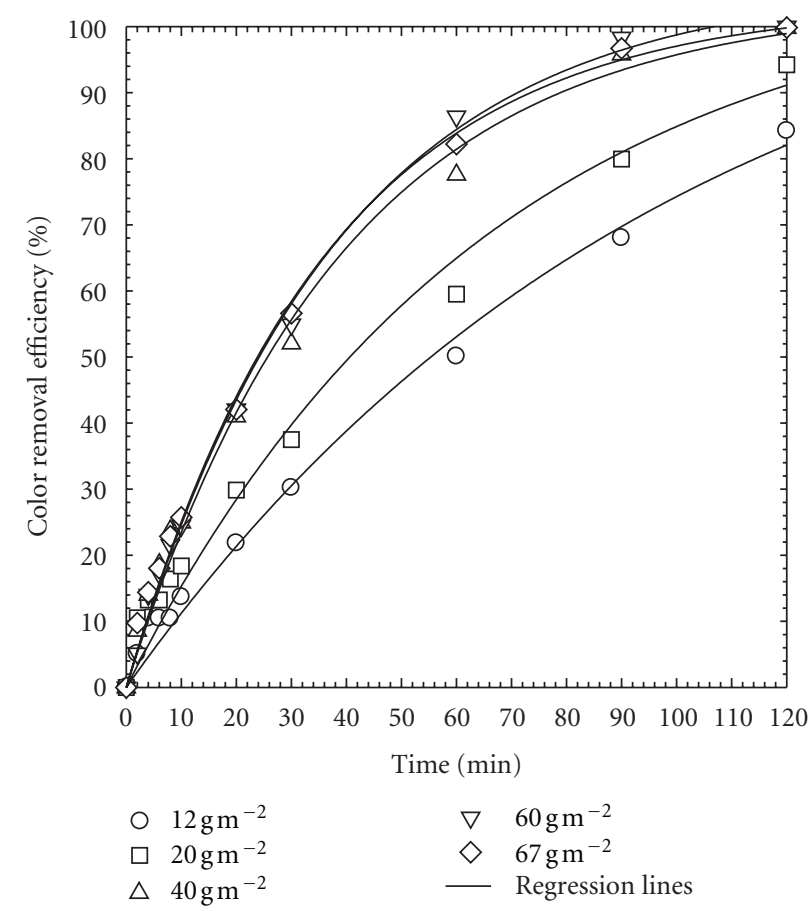

FIgure 5: Effect of surface loading of $\mathrm{TiO}_{2}$. The conditions were initial dye concentration of $50 \mathrm{mg} \mathrm{L}^{-1}$, light intensity of $2.1 \mathrm{~mW} \mathrm{~cm}^{-2}$, and reaction time during $120 \mathrm{~min}$.

Figure 6 shows the change of dye concentration as a function of time at various $\mathrm{pH}$ values. Results indicated that the color removal increased rapidly at acidic $\mathrm{pH}$ of 2 and 3 then became slow as the $\mathrm{pH}$ increased. This could be attributed to loss of hydroxyl radicals as $\mathrm{pH}$ increased. The effect of $\mathrm{pH}$ on the photodegradation of acid dye can be better described by the interaction between the dye compound and the photocatalyst. Better contact between the dye chemical and $\mathrm{TiO}_{2}$ is necessary for the degradation reaction. As $\mathrm{pH}$ increases, the surface of $\mathrm{TiO}_{2}$ becomes negatively charged. (note: the $\mathrm{pH}_{2 \mathrm{pc}}$ of $\mathrm{TiO}_{2}$ is 5.5). Negatively charged $\mathrm{TiO}_{2}$ surface discourages the adsorption of the anion acid dye. The rate constants followed similar trend to that of color removal. The rate constants at $\mathrm{pH} 2$ and 3 were 13.28 and $16.6\left(10^{-2} \mathrm{~min}^{-1}\right)$, respectively, which were greater than 2.69 $\left(10^{-2} \mathrm{~min}^{-1}\right)$ at $\mathrm{pH} 4$ as shown in Table 3(c). At original $\mathrm{pH}$ 5.3 , the degradation of OG dye was sufficient fast and reached $100 \%$ removal during 120 min reaction time. Furthermore, the effluent from acid dye bath dyeing processing (OG dye was applied) usually presents acidic $\mathrm{pH}$ at about 3-4. Thus, it is not suggested that the wastewater treatment plan adjust $\mathrm{pH}$ to 2-3 for better treatment efficiency. But it is encouraged to use the advantage of acid dye bath at acidic $\mathrm{pH}$ to elevate the reaction rate and removal efficiency.

3.5. Effect of Dye Initial Concentration. To present the validity of $\mathrm{L}-\mathrm{H}$ model on our $\mathrm{CCFL} / \mathrm{TiO}_{2}$ system, the effect of initial dye concentrations on the photodegradation of azo OG dye was studied at initial concentrations of $12.5-75 \mathrm{mg} \mathrm{L}^{-1}$, $\mathrm{TiO}_{2}$ dosage of $60 \mathrm{~g} \mathrm{~m}^{-2}$ and 6 CCFL lamps for a period of 


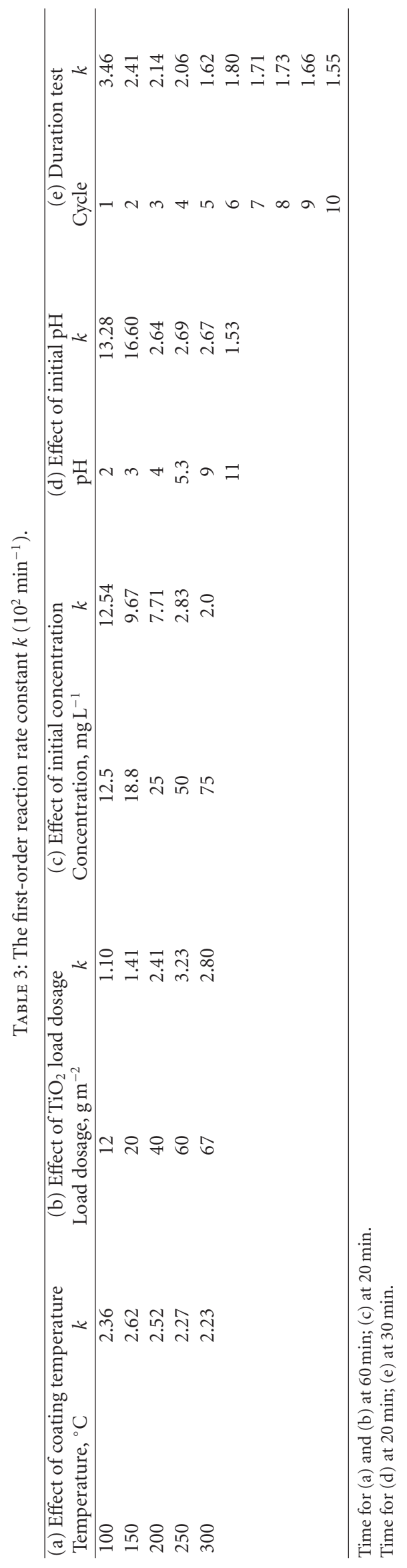




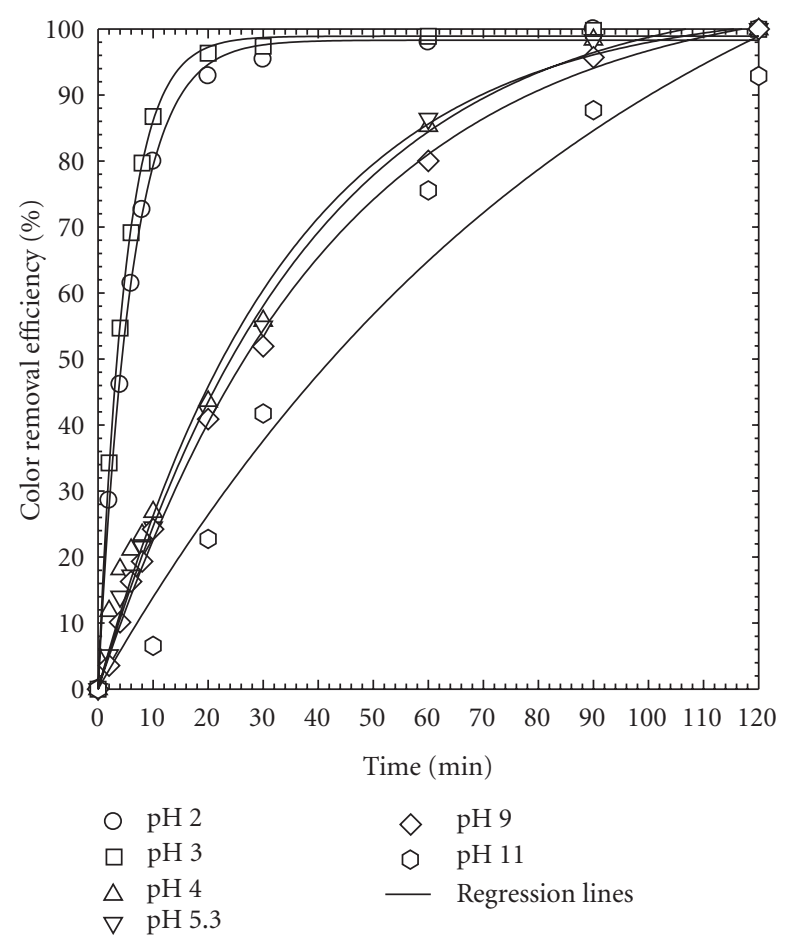

Figure 6: Effect of initial pH. The conditions were $\mathrm{TiO}_{2}$-coated amounts of $60 \mathrm{~g} \mathrm{~m}^{-2}$, light intensity of $2.1 \mathrm{~mW} \mathrm{~cm}^{-2}$, and reaction time during $120 \mathrm{~min}$.

$120 \mathrm{~min}$ in the closed reactor. Figure 7 shows results of dye photodegradation as a function of reaction time at various initial dye concentrations. Results indicated that the rate of dye removal decreased from 12.54 to $2.0\left(10^{-2} \mathrm{~min}^{-1}\right)$ when the initial dye concentration was increased from 12.5 to $75 \mathrm{mg} \mathrm{L}^{-1}$ as shown in Table 3(d). The rate constant then remained constant and independent of the dye concentration as the initial dye concentration increased to greater than $50 \mathrm{mg} \mathrm{L}^{-1}$. This is typical Langmuir-Hinshelwood (L-H) reaction kinetics which is generally capable for modeling $\mathrm{UV} / \mathrm{TiO}_{2}$ photocatalytic oxidation process [24-27]. According to the $\mathrm{L}-\mathrm{H}$ reaction kinetics, the rate of dye degradation can be described by the following equation:

$$
r=\frac{d C}{d t}=\frac{k K_{A} C}{1+K_{A} C}
$$

where $r$ is the degradation rate of dye $\left(\mathrm{mg} \mathrm{L}^{-1} \mathrm{~min}^{-1}\right), k$, $K_{A}$, and $C$ are the rate constant $\left(\mathrm{mg} \mathrm{L}^{-1} \mathrm{~min}^{-1}\right)$, equilibrium adsorption constant $\left(\mathrm{L} \mathrm{mg}^{-1}\right)$, and residual dye concentration $\left(\mathrm{mg} \mathrm{L}^{-1}\right)$, respectively. According to the above equation, at high dye concentration, that is, $1 \ll K C$, the rate equation is

$$
r=k
$$

Likewise, at low dye concentration, that is, $1 \gg K C$, (2) becomes

$$
r=k K_{A} C
$$

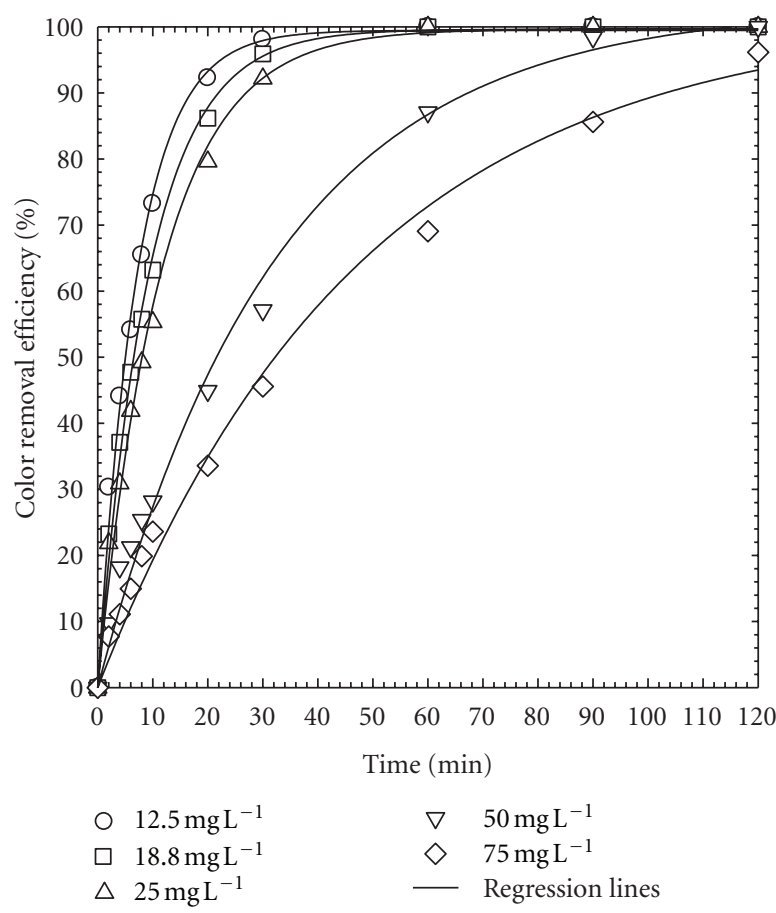

FIgURE 7: Effect of initial concentration. The conditions were $\mathrm{TiO}_{2}$ coated amounts of $60 \mathrm{~g} \mathrm{~m}^{-2}$, light intensity of $2.1 \mathrm{~mW} \mathrm{~cm}^{-2}$, and reaction time during $0 \sim 120 \mathrm{~min}$.

That is, as the initial concentration increases, the reaction no longer follows the first order expression; rather it becomes independent of the dye concentration as shows in (3). By rearranging (2), one has

$$
\frac{1}{r_{0}}=\frac{1}{k K_{A}} \times \frac{1}{C_{0}}+\frac{1}{k}
$$

where $r_{0}$ and $C_{0}$ are the initial rate $\left(\mathrm{mg} \mathrm{L}^{-1} \mathrm{~min}^{-1}\right)$ and initial dye concentration $\left(\mathrm{mg} \mathrm{L}^{-1}\right)$, respectively. A plot of the reciprocals of initial rate and initial concentration yields the rate constant, $k$, and the adsorption constant, $K$ (Figure 8). The initial rate $r_{0}$ was calculated by the first 2 min of Figure 7 with $\mathrm{TiO}_{2}$ loading dosage at 12 and $60 \mathrm{~g} \mathrm{~m}^{-2}$, respectively (Table 4$)$. From the slope $\left(1 / k K_{A}\right)$ and the intercept $(1 / k)$ of Figure 8 , the calculated $k$ and $K_{A}$ were $2.08 \mathrm{mg} \mathrm{L}^{-1} \mathrm{~min}^{-1}$ and $0.1257 \mathrm{~L} \mathrm{mg}^{-1}$ for $\mathrm{TiO}_{2}$ loading dosage at $12 \mathrm{~g} \mathrm{~m}^{-2}$ and $4.41 \mathrm{mg} \mathrm{L}^{-1} \mathrm{~min}^{-1}$ and $0.0346 \mathrm{~L} \mathrm{mg}^{-1}$ at $60 \mathrm{~g} \mathrm{~m}^{-2}$, respectively. The rate constants $(k)$ obtained in this work of 2.08 and $4.41 \mathrm{mg} \mathrm{L}^{-1} \mathrm{~min}^{-1}$ were higher than that of previous works [24-27] such as 1.66, 1.67, 0.95 , and $0.17 \mathrm{mg} \mathrm{L}^{-1} \mathrm{~min}^{-1}$ for various dyes direct red 16 , remazol black 5, procion red MX-5B, and indigo carmine, respectively. Similarly, the equilibrium adsorption constants $\left(K_{A}\right)$ of 0.1257 and $0.0346 \mathrm{~L} \mathrm{mg}^{-1}$ from this wok were in the range of previous studies, such as 0.0093, 0.072, 0.071, and $0.78 \mathrm{~L} \mathrm{mg}^{-1}$ for various dyes as above. The results indicate that the photocatalytic degradation of Orange $G$ by $\mathrm{CCFL} / \mathrm{TiO}_{2}$ process followed the Langmuir-Hinshelwood kinetic model. 


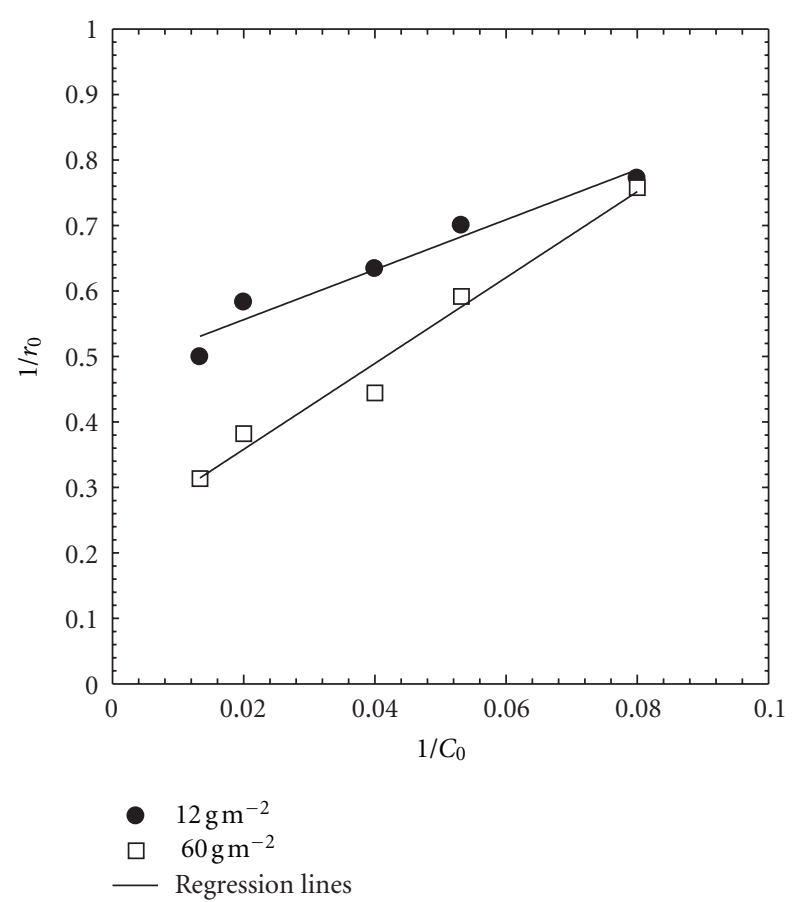

Figure 8: Langmuir-Hinshelwood kinetic model (comparison of two different $\mathrm{TiO}_{2}$ loading dosage of 12 and $60 \mathrm{~g} \mathrm{~m}^{-2}$ with light intensity of $2.1 \mathrm{~mW} \mathrm{~cm}^{-2}$ ).

TABLe 4: The effect of dye concentration on initial rate $r_{0}$ $\left(\mathrm{mg} \mathrm{L}^{-1} \mathrm{~min}^{-1}\right)$ with $\mathrm{TiO}_{2}$ loading dosage at 12 and $60 \mathrm{~g} \mathrm{~m}^{-2}$.

\begin{tabular}{lccccc}
\hline OG concentration, & 12.5 & 18.8 & 25 & 50 & 75 \\
$C_{0}\left(\mathrm{mg} \mathrm{L}^{-1}\right)$ & 1.30 & 1.43 & 1.58 & 1.72 & 2.00 \\
\hline$r_{0}-12 \mathrm{~g} \mathrm{~m}^{-2}$ & 1.32 & 1.69 & 2.25 & 2.62 & 3.19 \\
\hline
\end{tabular}

3.6. The Product Analysis by FTIR and IC. The change of functional groups of azo dye after photocatalytic treatment was surveyed. The initial dye concentration was $50 \mathrm{mg} \mathrm{L}^{-1}$ and was treated with a $\mathrm{TiO}_{2}$ dosage of $60 \mathrm{~g} \mathrm{~m}^{-2}$ and reaction time of $120 \mathrm{~min}$. The scan spectra for the functional groups is $\mathrm{SO}_{3} \mathrm{Na}$ of $1150 \sim 1250 \mathrm{~cm}^{-1}, \mathrm{~N}=\mathrm{N}$ of $1400 \sim 1500 \mathrm{~cm}^{-1}, \mathrm{C}=\mathrm{O}$ of $1690 \sim 1760 \mathrm{~cm}^{-1}, \mathrm{C}-\mathrm{H}$, and $\mathrm{N}-\mathrm{H}$ of $3300 \sim 3500 \mathrm{~cm}^{-1}$. The residual color was 0 and the residual TOC was $2.13 \mathrm{mg} \mathrm{L}^{-1}$. After the photocatalytic oxidation, a new double-bond $\mathrm{C}=\mathrm{O}$ at $1637 \mathrm{~cm}^{-1}$ was produced. Meanwhile the $\mathrm{N}=\mathrm{N}$ from dye at 1426,1463 , and $1496 \mathrm{~cm}^{-1}$ disappeared due to attack by the hydroxyl radicals that cleaved the doublebond $\mathrm{N}=\mathrm{N}$. Accordingly, the dye molecule was degraded and decolorized. The ions such as sulfate, chloride, nitrite, and nitrate were determined. Figure 9 shows that the major ion concentration of sulfate significantly increased to $11 \mathrm{mg} \mathrm{L}^{-1}$ over time. The nitrate ion concentration was about 0.4 to $0.5 \mathrm{mg} \mathrm{L}^{-1}$ and nitrite concentration was low at $0.1 \mathrm{mg} \mathrm{L}^{-1}$. The chloride ion produced due to the impurity of OG dye was low as $1.5 \mathrm{mg} \mathrm{L}^{-1}$.

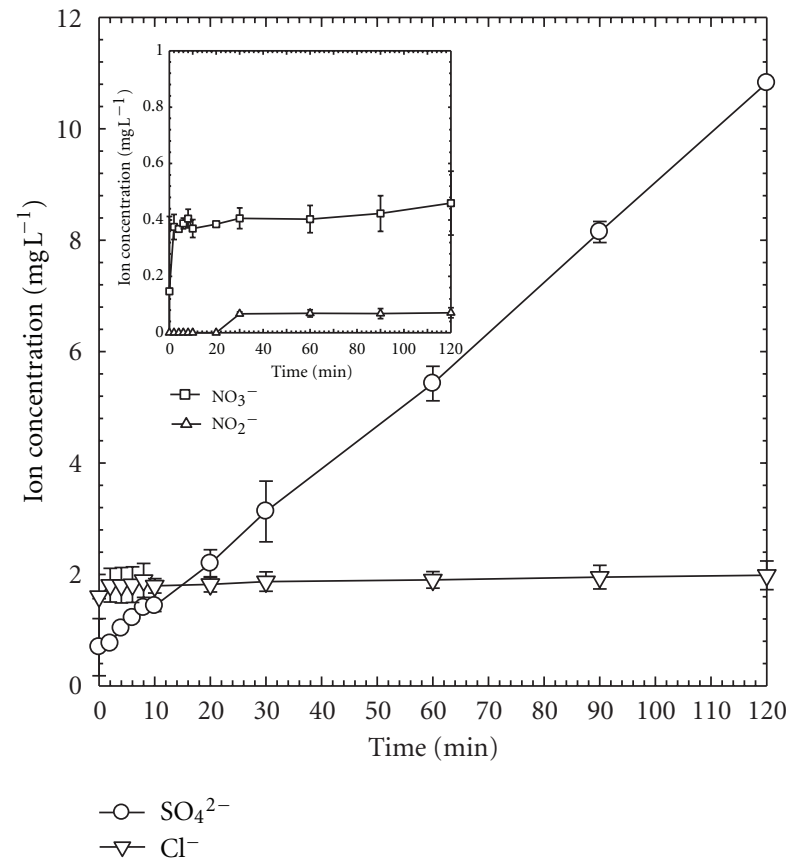

Figure 9: The product analysis by IC. The conditions were initial dye concentration of $50 \mathrm{mg} \mathrm{L}^{-1}, \mathrm{TiO}_{2}$-coated amounts of $60 \mathrm{~g} \mathrm{~m}^{-2}$, and light intensity of $2.1 \mathrm{~mW} \mathrm{~cm}^{-2}$ at $120 \mathrm{~min}$.

3.7. Application Duration. The $\mathrm{TiO}_{2}$-coated steel mesh was used repeatedly to treat the OG solution. Figure 10 shows the system performance over 10 cycles. Results indicated that although the rate of OG degradation decreased as the reuse cycle of catalyst increased, the total amount of dye removal remained relatively unchanged at $100 \%$ in the treatment time range of 100-120 $\mathrm{min}$, however. In the meantime, there was nearly no loss of $\mathrm{TiO}_{2}$ in each operation even after 10 cycles. The observed rate constants declined with more reuse cycles as shown in Table 3(e), however. This can be attributed to potential surface poisoning of the photocatalyst, $\mathrm{TiO}_{2}$ due to adsorption of reaction products. Further investigation is in progress to assess the reactivity of the $\mathrm{TiO}_{2}$ during the course of photocatalytic reactions.

\section{Conclusions}

$\mathrm{TiO}_{2}$ supported on steel mesh and illuminated with cold cathode fluorescent light (CCFL) was effective in removal color and dye from the OG azo dye solution. Coating $\mathrm{TiO}_{2}$ at $150^{\circ} \mathrm{C}$ yielded the fastest color removal rate. An optimal $\mathrm{TiO}_{2}$ surface loading or dosage of $60 \mathrm{~g} \mathrm{~m}^{-2}$ exhibited the highest color removal as well as the fastest rate; increase in surface $\mathrm{TiO}_{2}$ loading had no benefit in increasing the color removal, however. An acidic $\mathrm{pH}$ of 2-3 had the best photocatalytic oxidation rate; the rate of color removal decreased when $\mathrm{pH}$ was increased to greater than 4 . The rate of color removal decreased with initial dye concentration as was expected by the Langmuir-Hinshelwood kinetics. Based on FTIR analysis, there was decrease of $\mathrm{N}=\mathrm{N}$ bonding which indicated chemical transformation of the dye OG 


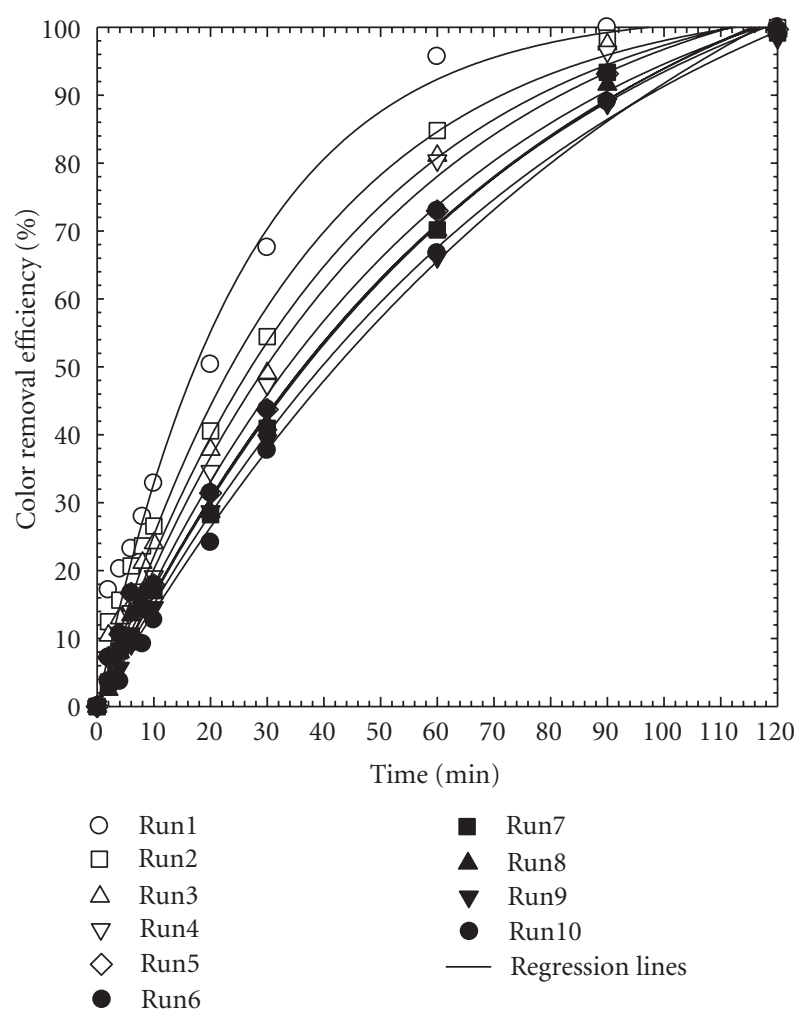

Figure 10: Duration test on color removal. The conditions were initial dye concentration of $50 \mathrm{mg} \mathrm{L}^{-1}, \mathrm{TiO}_{2}$-coated amounts of $60 \mathrm{~g} \mathrm{~m}^{-2}$, light intensity of $2.1 \mathrm{~mW} \mathrm{~cm}^{-2}$, and reaction time during $120 \mathrm{~min}$.

compound. Results of analyzing the inorganic byproducts revealed that sulfate production was predominant; nitrite and nitrate were produced at minor quantities. The $\mathrm{TiO}_{2}$ coated steel mesh can be repeatedly used over 10 cycles without significant loss of catalyst mass; the percent dye removal remained close to $100 \%$ in 10 cycles except slight decrease in reaction rate constants apparently due to possible surface poisoning. In general, the new photocatalytic system showed great potential in ease of implementation and cost for the treatment of dye industrial wastewater for color removal.

\section{Acknowledgments}

The authors appreciate the partial research funding granted by the Taiwan National Science Foundation (NSC 97-2918I-241-001 and NSC 96-2221-E-241-005-MY2) as well as the analysis by NSC instrumental center of National Chung Hsing University and National Tsing Hua University.

\section{References}

[1] M. A. Brown and S. C. DeVito, "Predicting azo dye toxicity," Critical Reviews in Environmental Science and Technology, vol. 23, no. 3, pp. 249-324, 1993.

[2] H. Y. Shu, C. R. Huang, and M. C. Chang, "Decolorization of mono-azo dyes in wastewater by advanced oxidation process: a case study of acid red 1 and acid yellow 23," Chemosphere, vol. 29, no. 12, pp. 2597-2607, 1994.

[3] B. Manu and S. Chaudhari, "Decolorization of indigo and azo dyes in semicontinuous reactors with long hydraulic retention time," Process Biochemistry, vol. 38, no. 8, pp. 1213-1221, 2003.

[4] J. Ge and J. Qu, "Ultrasonic irradiation enhanced degradation of azo dye on $\mathrm{MnO}_{2}$," Applied Catalysis B, vol. 47, no. 2, pp. 133-140, 2009.

[5] C. M. Kao, M. S. Chou, W. L. Fang, B. W. Liu, and B. R. Huang, "Regulating colored textile wastewater by $3 / 31$ wavelength admi methods in Taiwan," Chemosphere, vol. 44, no. 5, pp. 1055-1063, 2001.

[6] H. Y. Shu, M. C. Chang, and H. J. Fan, "Decolorization of azo dye acid black 1 by the $\mathrm{UV} / \mathrm{H}_{2} \mathrm{O}_{2}$ process and optimization of operating parameters," Journal of Hazardous Materials, vol. 113, no. 1-3, pp. 201-208, 2004.

[7] H. Y. Shu, M. C. Chang, and H. J. Fan, "Effects of gap size and UV dosage on decolorization of C.I. Acid Blue 113 wastewater in the UV/ $\mathrm{H}_{2} \mathrm{O}_{2}$ process," Journal of Hazardous Materials, vol. 118, no. 1-3, pp. 205-211, 2005.

[8] H. Y. Shu, M. C. Chang, and W. P. Hsieh, "Remedy of dye manufacturing process effluent by $\mathrm{UV} / \mathrm{H}_{2} \mathrm{O}_{2}$ process," Journal of Hazardous Materials, vol. 128, no. 1, pp. 60-66, 2006.

[9] E. Rodríguez, R. Peche, J. M. Merino, and L. M. Camarero, "Decoloring of aqueous solutions of indigocarmine dye in an acid medium by $\mathrm{H}_{2} \mathrm{O}_{2} / \mathrm{UV}$ advanced oxidation," Environmental Engineering Science, vol. 24, no. 3, pp. 363-371, 2007.

[10] H. Y. Shu and M. C. Chang, "Decolorization effects of six azo dyes by $\mathrm{O}_{3}, \mathrm{UV} / \mathrm{O}_{3}$ and $\mathrm{UV} / \mathrm{H}_{2} \mathrm{O}_{2}$ processes," Dyes and Pigments, vol. 65, no. 1, pp. 25-31, 2005.

[11] C. H. Wu and H. Y. Ng, "Degradation of C.I. Reactive Red 2 (RR2) using ozone-based systems: comparisons of decolorization efficiency and power consumption," Journal of Hazardous Materials, vol. 152, no. 1, pp. 120-127, 2008.

[12] T. H. Kim, C. Park, J. Yang, and S. Kim, "Comparison of disperse and reactive dye removals by chemical coagulation and Fenton oxidation," Journal of Hazardous Materials, vol. 112, no. 1-2, pp. 95-103, 2004.

[13] F. Ay, E. C. Catalkaya, and F. Kargi, "Advanced oxidation of direct red (DR 28) by fenton treatment," Environmental Engineering Science, vol. 25, no. 10, pp. 1455-1462, 2008.

[14] A. T. Toor, A. Verma, C. K. Jotshi, P. K. Bajpai, and V. Singh, "Photocatalytic degradation of Direct Yellow 12 dye using $\mathrm{UV} / \mathrm{TiO}_{2}$ in a shallow pond slurry reactor," Dyes and Pigments, vol. 68 , no. 1 , pp. 53-60, 2006.

[15] M. Muruganandham and M. Swaminathan, "Photocatalytic decolourisation and degradation of Reactive Orange 4 by $\mathrm{TiO}_{2}$-UV process," Dyes and Pigments, vol. 68, no. 2-3, pp. 133-142, 2006.

[16] X. Yin, F. Xin, F. Zhang, S. Wang, and G. Zhang, "Kinetic study on photocatalytic degradation of 4BS Azo dye over $\mathrm{TiO}_{2}$ in slurry," Environmental Engineering Science, vol. 23, no. 6, pp. 1000-1008, 2006.

[17] A. Akyol and M. Bayramoglu, "The degradation of an azo dye in a batch slurry photocatalytic reactor," Chemical Engineering and Processing, vol. 47, no. 12, pp. 2150-2156, 2008.

[18] R. B. M. Bergamini, E. B. Azevedo, and L. R. R. D. Araújo, "Heterogeneous photocatalytic degradation of reactive dyes in aqueous $\mathrm{TiO}_{2}$ suspensions: decolorization kinetics," Chemical Engineering Journal, vol. 149, no. 1-3, pp. 215-220, 2009.

[19] G. Mascolo, R. Comparelli, M. L. Curri, G. Lovecchio, A. Lopez, and A. Agostiano, "Photocatalytic degradation of methyl red by $\mathrm{TiO}_{2}$ : comparison of the efficiency of immobilized nanoparticles versus conventional suspended catalyst," 
Journal of Hazardous Materials, vol. 142, no. 1-2, pp. 130-137, 2007.

[20] B. Mounir, M. N. Pons, O. Zahraa, A. Yaacoubi, and A. Benhammou, "Discoloration of a red cationic dye by supported $\mathrm{TiO}_{2}$ photocatalysis," Journal of Hazardous Materials, vol. 148, no. 3, pp. 513-520, 2007.

[21] M. Nikazar, K. Gholivand, and K. Mahanpoor, "Photocatalytic degradation of azo dye Acid Red 114 in water with $\mathrm{TiO}_{2}$ supported on clinoptilolite as a catalyst," Desalination, vol. 219, no. 1-3, pp. 293-300, 2008.

[22] A. R. Khataee, M. N. Pons, and O. Zahraa, "Photocatalytic degradation of three azo dyes using immobilized $\mathrm{TiO}_{2}$ nanoparticles on glass plates activated by UV light irradiation: influence of dye molecular structure," Journal of Hazardous Materials, vol. 168, no. 1, pp. 451-457, 2009.

[23] X. Wang, Y. Liu, Z. Hu, Y. Chen, W. Liu, and G. Zhao, "Degradation of methyl orange by composite photocatalysts nano- $\mathrm{TiO}_{2}$ immobilized on activated carbons of different porosities," Journal of Hazardous Materials, vol. 169, no. 1-3, pp. 1061-1067, 2009.

[24] T. Aarthi, P. Narahari, and G. Madras, "Photocatalytic degradation of Azure and Sudan dyes using nano $\mathrm{TiO}_{2}$," Journal of Hazardous Materials, vol. 149, no. 3, pp. 725-734, 2007.

[25] K. Sahel, N. Perol, H. Chermette, C. Bordes, Z. Derriche, and C. Guillard, "Photocatalytic decolorization of Remazol Black 5 (RB5) and Procion Red MX-5B-Isotherm of adsorption, kinetic of decolorization and mineralization," Applied Catalysis B, vol. 77, no. 1-2, pp. 100-109, 2007.

[26] N. Barka, A. Assabbane, A. Nounah, and Y. A. Ichou, "Photocatalytic degradation of indigo carmine in aqueous solution by $\mathrm{TiO}_{2}$-coated non-woven fibres," Journal of Hazardous Materials, vol. 152, no. 3, pp. 1054-1059, 2008.

[27] J. Saien, M. Asgari, A. R. Soleymani, and N. Taghavinia, "Photocatalytic decomposition of direct red 16 and kinetics analysis in a conic body packed bed reactor with nanostructure titania coated Raschig rings," Chemical Engineering Journal, vol. 151, no. 1-3, pp. 295-301, 2009. 


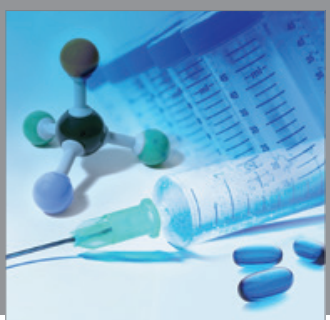

International Journal of

Medicinal Chemistry

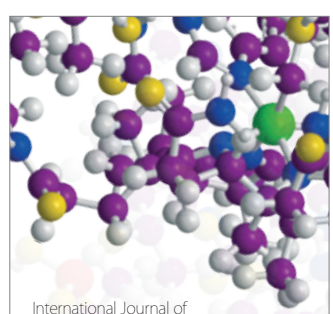

Carbohydrate Chemistry

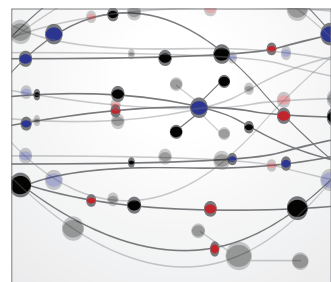

The Scientific World Journal
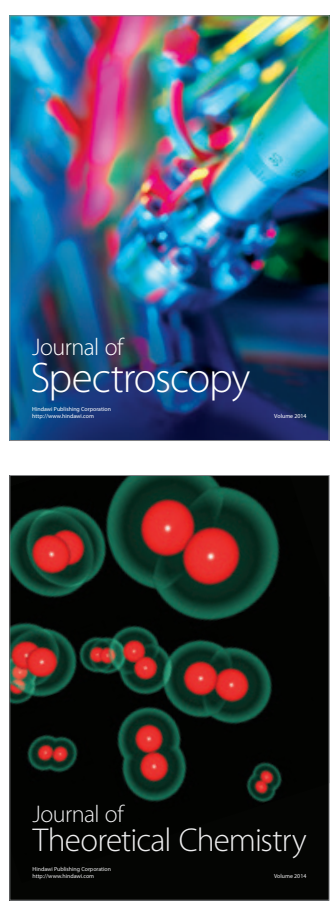
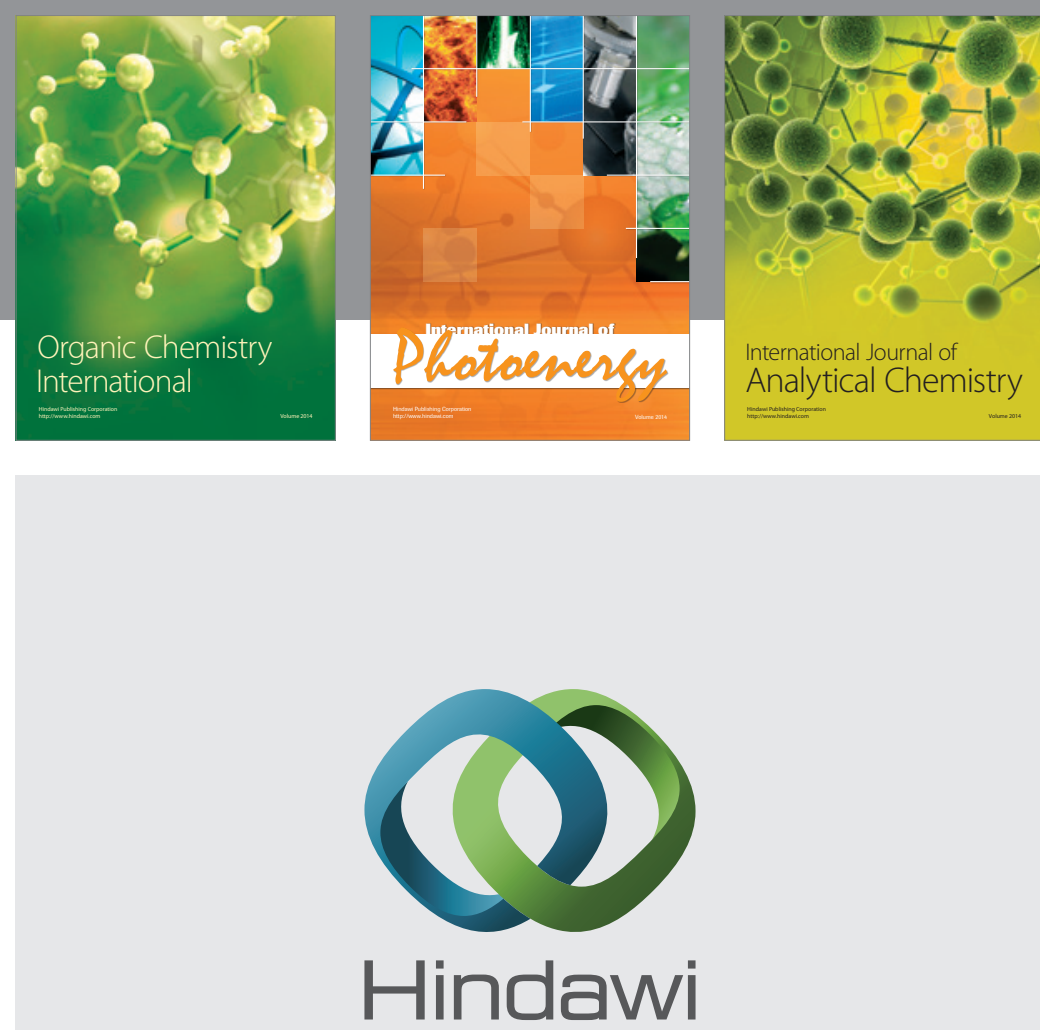

Submit your manuscripts at

http://www.hindawi.com
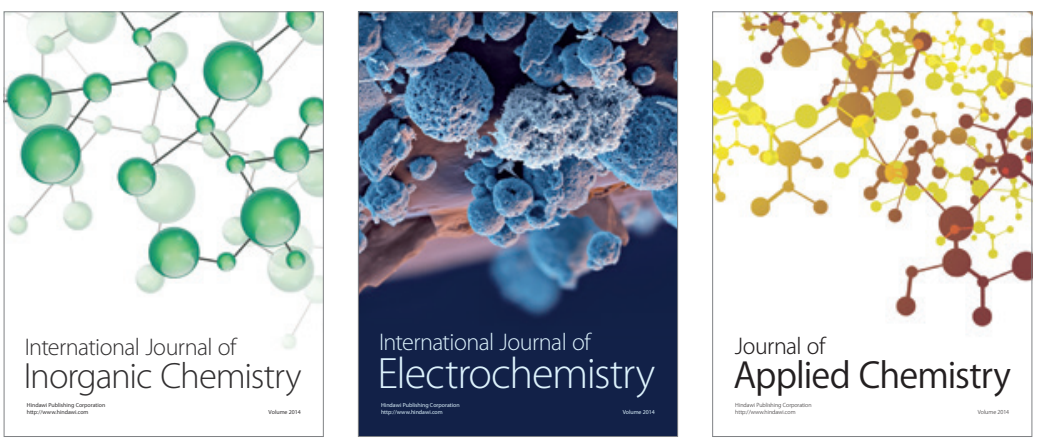

Journal of

Applied Chemistry
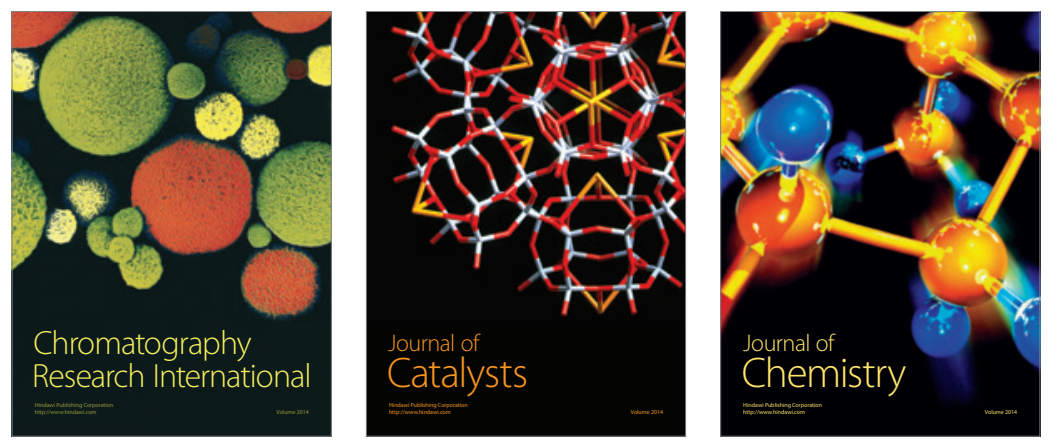
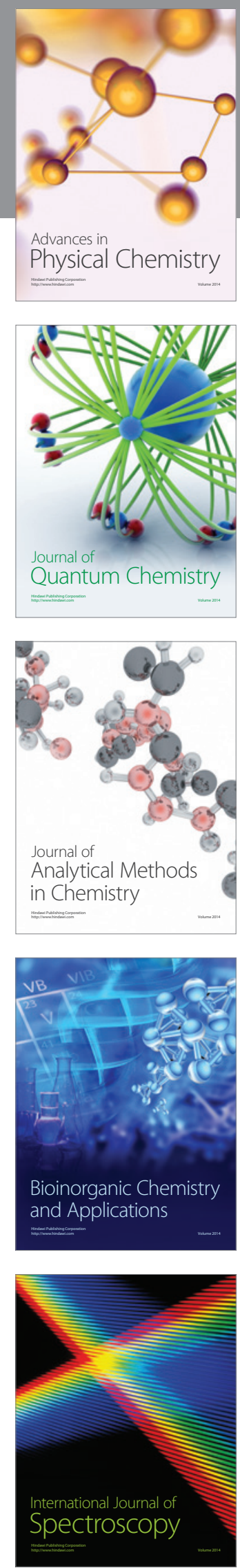